\title{
TEMPOROMANDIBULAR JOINT MORPHOLOGY AT ORTHOGNATIC BITE
}

\section{A.R. Arushanyan', V.V. Konnov' ${ }^{1}$ A.P. Vedyaeva ${ }^{2}$, D.Kh. Razakov', T.V. Matytsina', D.N. Maslennikov', R.N. Mukhamedov' , A.S. Khodorich', I.V. Matytsina ${ }^{1}$}

\author{
${ }^{1}$ Department of Orthopedic Dentistry; Saratov State Medical University, \\ Ministry of Healthcare of Russian Federation; \\ Russia, 112, Bolshaya Kazachya Street, Saratov, 410012. \\ E-mail: konnovvaleriy@rambler.ru, tel: +79170265176. \\ 2 Department of Dentistry, Sechenov University; Department of \\ Periodontology, Federal State Institution Central Research Institute of \\ Dental and Maxillofacial Surgery, \\ tel: +7903 3284465; E-mail:vandrer@mail.ru
}

\section{INTRODUCTION}

The parameters of the temporomandibular joint normal structure make an important piece of knowledge in common dental practice, primarily because it is some kind of a benchmark that allows making correct judgment concerning changes in the temporomandibular joint occurring through various diseases and prosthetic events that entail new ratios not only in the dentition area, yet also in the temporomandibular joint area [1-12].

Aim of study

To clarify the patterns of shape and size for the major morphological elements of the temporomandibular joint in case of the orthognathic bite.

\section{Materials and methods}

The study of the temporomandibular joint was conducted on 19 skulls of males and females (aged 20-44) obtained from the research craniological collection of the Human Anatomy Department, Saratov State Medical University named after V.I. Razumovsky.

\section{RESULTS}

Our study has confirmed that a normal temporomandibular joint features regular shape and size in its structural elements, namely, the articular fossa is of an elliptical shape with its anterior boundary being the articular tubercle posterior surface, the posterior boundary - the posterior articular process and the temporal bone tympanic part, from inside - with lateral edge of the main bone process, and from outside - the ridge of the temporal bone zygomatic process. The transverse diameter of the articular fossa varies between 20 and $29 \mathrm{~mm}$ with the average value being
$24.5 \mathrm{~mm}$. The articular fossa average sagittal diameter is $16.5 \mathrm{~mm}$. The transverse diameter's ratio to the articular fossa sagittal diameter is $1.5: 1$. The average depth of the articular fossa is $8.5 \mathrm{~mm}$.

The articular tubercle on the temporal bone is elliptical with a varying height, from 5 to $14 \mathrm{~mm}$. The articular tubercle features three surfaces - posterior, on which the articular head travels; horizontal, representing the top of the articular tubercle and the front surface, which turns into the infratemporal fossa.

The mandibular articular head has a variable shape and features anterior, posterior and upper surfaces. The anterior surface is concave and serves as an attachment point for the lateral pterygoid muscle; the posterior surface of the articular head resembles a triangle and in all cases bears an imprint of the posterior articular process. The articular head upper surface resembles an ellipse with its longitudinal diameter of $19 \mathrm{~mm}$ and a transverse diameter of $8 \mathrm{~mm}$. Subject to our data, the mandible articular head's sagittal diameter ratio to the transverse diameter of the temporomandibular joint articular fossa is $1: 1.3$, and the ratio of the transverse diameter of the jaw articular head to the articular fossa sagittal diameter is 1:2. The incongruence of the mandibular articular head against the joint articular fossa is corrected by the articular disc, which is an oval-shaped biconcave plate, with a sagittal diameter reaching $20 \mathrm{~mm}$ and the transverse one $10 \mathrm{~mm}$. The upper concavity matches the bulge on the articular tubercle rear surface, and the lower concavity - the upper surface of the mandible articular head. This shape of the disc compensates the incongruence of the articular tubercle and that of the articular head. Anthropometric measurements show that the longitudinal and transverse diameters of the articular disk, as well as its thickness, are different in different areas, so the articular disk in its central part seems to be pressed from below by the upper surface of the articular head and from above by the posterior articular tubercle slope. The average disk thickness in this area is $1.2 \mathrm{~mm}$. The posterior part of the articular disk can be $3.5 \mathrm{~mm}$ $-5.3 \mathrm{~mm}$ thick.

\section{CONCLUSION}

Given the above, the temporomandibular joint of an adult person featuring an orthognathic bite can be described as having regular shape and size in its structural elements, while deviations from these allow 
judging the occurring changes as well as monitor the treatment and observe its long-term outcomes.

\section{REFERENCES}

\section{KOROBKEEV A.A., DOMENYUK D.A., SHKARIN} V.V., DMitrienko S.V., Weisheim L.D., KonNov V.V. Anatomical features of the interdependence of the basic parameters of the dental arches of the upper and lower jaws of man. Medical news of North Caucasus. 2018. - Vol. 13. - № 1-1. - P. 66-69. (In Russ., English abstract). DOI - https://doi.org/10.14300/ mnnc.2018.13019.

2. KorobKeEv A.A. Changes in the structural elements of the temporomandibular joint with distal occlusion / A.A. Korobkeev, D.A. Domenyuk, E.G. Vedeshina, V.V. Konnov, O.Yu. Lezhnina, Ya.A. Korobkeeva // Medical news of North Caucasus. 2017. - Vol. 12. № 1. - P. 72-76. (In Russ., English abstract). DOI https://doi.org/10.14300/mnnc.2017.12020.

3. DMitrienko S.V., Davydov B.N., V.V. ShKarin, DomenYuk D.A. Algorithm for determining the size of artificial teeth by the morphometric parameters of the face in people with full adentia. Dentistry. 2018; 97(6): 57-60. DOI - https://doi.org/10.17116/stomat20189706157.

4. Konnov V.V., Davydov B.N., Vedeshina E.G., DOMENYUK D.A. The morphology of the temporomandibular joint in normal occlusion and distal occlusion complicated by defects of dentitions (Part I). The Dental Institute. 2017; 74(1):92-94. (In Russ.).

5. Konnov V.V., Davydov B.N., Vedeshina E.G., DOMENYUK D.A. The morphology of the temporomandibular joint in normal occlusion and distal occlusion complicated by defects of dentitions (Part II). The Dental Institute. 2017; 75(2): 66-69. (In Russ.).

6. Efficiency of orthopedic methods for treating patients with dentition defects complicated by distal occlusion depending on the topographic features of the temporomandibular joint / V.V. Konnov, E.N. Pichugin, A.R. Arushanyan, A.A. Bizyaev, V.A. Mikayilova // Modern orthopedic dentistry. - 2017. - № 28. - P. 39-41.

7. Clinical image of temporomandibular joint dysfunction in patients with dentition defects complicated with displaced mandible / S.V. Konnov, E.N. Pichugina, V.V. Konnov, A.A. Bizyaev, S.N. Salnikova, A.R. Arushanyan, V.A. Mikailova // Archiv EuroMedica. - 2018. - V. 8, № 1. - P. 42-43.

8. Functional status of masticatory muscles at occlusion disturbances accompanied with displaced mandible / S.V. Konnov, D.Kh. Razakov, V.V. Konnov, A.R. Arushanyan, R.N. Mukhamedov, A.S. Khodorich, V.A. Mikailova // Archiv EuroMedica. - 2018. - V. 8, № 1. - P. 41-42.

9. Radiological specifics of temporomandibular joint structure in case of dentition issues complicated with distal occlusion / S.V. Konnov, A.A. Bizyaev, V.V. Konnov, E.V. Pichugina, S.N. Salnikova, A.S. Khodorich, V.A. Mikailova // Archiv EuroMedica. - 2018. - V. 8, № 1. - P. 39-40.
10. Specifics of occlusion disturbances in adults with distal occlusion due to dentition defects / S.V. Konnov, A.R. Arushanyan, V.V. Konnov, D.Kh. Razakov, R.N. Mukhamedov, E.N. Pichugina, V.A. Mikailova // Archiv EuroMedica. - 2018. V. 8, № 1. - P. 40-41.

11. Dynamic electrical neurostimulation in comprehensive treatment of temporomandibular joint pain syndrome in patients with occlusion issues / V.V. Konnov, D.Kh. Razakov, E.N. Pichugina, A.P. Vedyaeva, V.A. Mikailova, A.A. Bizyaev, S.N. Salnikova, E.S. Popko // Archiv EuroMedica. - 2018. - V. 8. № 2. - P. 115-119.

12. Domenyuk D.A., Konnov V.V., Pichugina E.N., ANFinogenova O.I., GonCharenko A.N., PushKIN S.V. Microcomputed tomography in qualitative and quantitative evaluation of dental enamel demineralization. Entomology and Applied Science Letters. 2018; 5(4): 72-83. 